\title{
NASA LANGLEY RESEARCH CENTER'S SIMULATION-TO-FLIGHT CONCEPT ACCOMPLISHED THROUGH THE INTEGRATION LABORATORIES OF THE TRANSPORT RESEARCH FACILITY
}

\author{
Debbie Martínez, ${ }^{*}$ Paul C. Davidson, ${ }^{\dagger}$ P. Sean Kenney, ${ }^{\dagger}$ and Brian K. Hutchinson ${ }^{\S}$ \\ Flight Research Services Competency/Flight Simulation and Software Branch
}

NASA Langley Research Center, Hampton, VA 23681

The Flight Simulation and Software Branch (FSSB) at NASA Langley Research Center (LaRC) maintains the unique national asset identified as the Transport Research Facility (TRF). The TRF is a group of facilities and integration laboratories utilized to support the LaRC's simulation-to-flight concept. This concept incorporates common software, hardware, and processes for both groundbased flight simulators and LaRC's B-757-200 flying laboratory identified as the Airborne Research Integrated Experiments System (ARIES). These assets provide Government, industry, and academia with an efficient way to develop and test new technology concepts to enhance the capacity, safety, and operational needs of the ever-changing national airspace system. The integration of the TRF enables a smooth continuous flow of the research from simulation to actual flight test.

\section{Nomenclature/Acronyms}

$\begin{array}{ll}\text { ASC } & \text { Aviation Systems Capacity program } \\ \text { AFD } & \text { Aft Flight Desk simulator cab } \\ \text { AILS } & \text { Airborne Information for Lateral Spacing project } \\ \text { ARIES } & \text { Airborne Research Integrated Experiments System } \\ \text { ARINC } & \text { Aeronautical Radio Incorporated } \\ \text { ATC } & \text { Air Traffic Control } \\ \text { AvSP } & \text { Aviation Safety Program } \\ \text { AWIN } & \text { Aviation Weather Information } \\ \text { CDU } & \text { Computer Display Unit } \\ \text { CFIT } & \text { Controlled Flight Into Terrain accidents } \\ \text { CM } & \text { Configuration Management } \\ \text { CMF } & \text { Cockpit Motion Facility } \\ \text { DAS } & \text { Data Acquisition Systems } \\ \text { DFW } & \text { Dallas Fort Worth airport } \\ \text { DMS } & \text { Differential Maneuvering Simulator } \\ \text { DOF } & \text { Degree Of Freedom }\end{array}$

* Computer Engineer, FRSC/FSSB, NASA LaRC, MS 125B, Hampton, VA.

${ }^{\dagger}$ Electronics Engineer, FRSC/FSSB, NASA LaRC, MS 125B, Hampton, VA.

* Aerospace Engineer, FRSC/FSSB, NASA LaRC, MS 125B, Hampton, VA.

$\S$ Computer Engineer, FRSC/FSSB, NASA LaRC, MS 125B, Hampton, VA. 


\begin{tabular}{|c|c|}
\hline EDCP & Experimental Display Control Panel \\
\hline ESIG & Evans-Sutherland Image Generator \\
\hline FCI & Flight Controls Interface \\
\hline FDRS & Flight Deck Research Station \\
\hline FFD & Forward Flight Deck \\
\hline FMC & Flight Management Computer \\
\hline FMS & Flight Management System \\
\hline FRSC & Flight Research Services Competency \\
\hline FSIL & Flight System Integration Laboratory \\
\hline FSSB & Flight Simulation and Software Branch \\
\hline Gs & Gravitational (number of) \\
\hline GFD & Generic Flight Deck simulator cab \\
\hline GPS & Global Positioning System \\
\hline HDD & Head Down Display \\
\hline HUD & Head Up Display \\
\hline IFD & Integration Flight Deck simulator cab \\
\hline $\mathrm{I} / \mathrm{O}$ & Input/Output \\
\hline IOC & I/O Concentrator \\
\hline LaRC & Langley Research Center \\
\hline NASA & National Aeronautics and Space Administration \\
\hline NTS & Network Transparent Switch \\
\hline OPS & Operators console \\
\hline PIP & Product Improvement Package \\
\hline PSP & Pilot Selection Panel \\
\hline RFD & Research Flight Deck simulator cab \\
\hline RIPS & Runway Incursion Prevention System \\
\hline RSIL & Research System Integration Laboratory \\
\hline SATCOM & Satellite Communication \\
\hline SCRAMNet ${ }^{\text {S }}+$ & Shared Common Random Access Memory Network \\
\hline $\mathrm{SGI} \circledast$ & Silicon Graphics $®$ Incorporated \\
\hline SVS & Synthetic Vision Systems project \\
\hline TAP & Terminal Area Productivity project \\
\hline TCAS & Traffic Alert and Collision Avoidance \\
\hline TFP & Time Frequency Processor \\
\hline TGIR & Turning Goals into Reality Award \\
\hline TMSP & Thrust Mode Select Panel \\
\hline TPAWS & Turbulence Prediction and Warning System program \\
\hline TRF & Transport Research Facility \\
\hline TRS & Transport Research System \\
\hline UTC & Universal Time Code \\
\hline VME & Versabus Module Europe \\
\hline VMS & Visual Motion Simulator \\
\hline WxAP & Weather Accident Prevention project \\
\hline
\end{tabular}




\section{Introduction}

The mission of NASA LaRC's Flight Simulation and Software Branch (FSSB) is to support research in aerospace vehicles and systems technologies by designing, implementing, testing, and validating research concepts in its flight simulators and by providing software to support flight research projects. FSSB has participated in numerous research projects involving commercial transports, general aviation, military aircraft and unmanned aerial vehicles.

In the past, software developed for simulation research projects at NASA LaRC required re-engineering to operate on the research aircraft computer systems. The re-engineering process was inefficient in terms of both time and cost; and differences in the implementations were difficult to manage. To solve the problem the Simulation-To-Flight concept was created which helped to streamline and thereby standardize the transition of projects from the simulation environment to the flight environment. A key component in the new concept was the existence of two nearly identical integration laboratories, one for simulation research and one for flight integration. The Research System Integration Laboratory (RSIL) and the Flight System Integration Laboratory (FSIL) are joined with NASA's Boeing 757-200 aircraft (a.k.a., Airborne Research Integrated Experiments System, or ARIES) to establish the Transport Research Facility (TRF) as shown in Figure 1 .

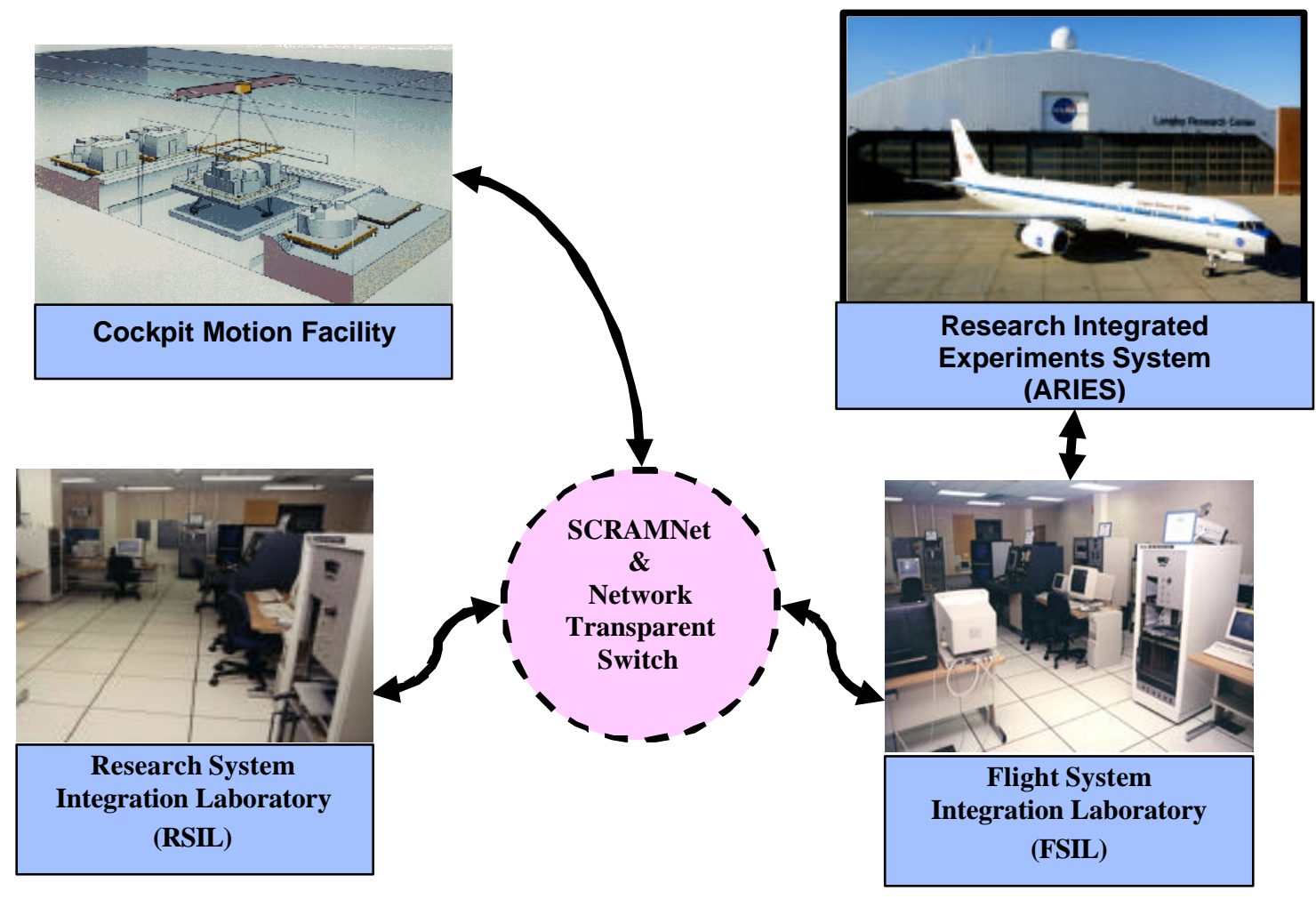

Figure 1 - Transport Research Facility (TRF)

Figure 2 illustrates the Simulation-To-Flight concept which allows flight research (hardware and/or software) projects to be developed in the simulation environment until its research models and/or components have been determined to be ready for further investigation in a flight environment. This concept is achieved by utilizing common software and hardware, procedures, and processes for both piloted-simulation and flight testing. [1] The RSIL and FSIL allow the research models to be thoroughly tested, in as close to an operational flight environment as possible, thereby providing for a more reliable and cost effective utilization of resources. The remainder of this paper will present the RSIL and FSIL 
architecture, how they are utilized within the TRF, and how these laboratories have impacted air transportation safety research.

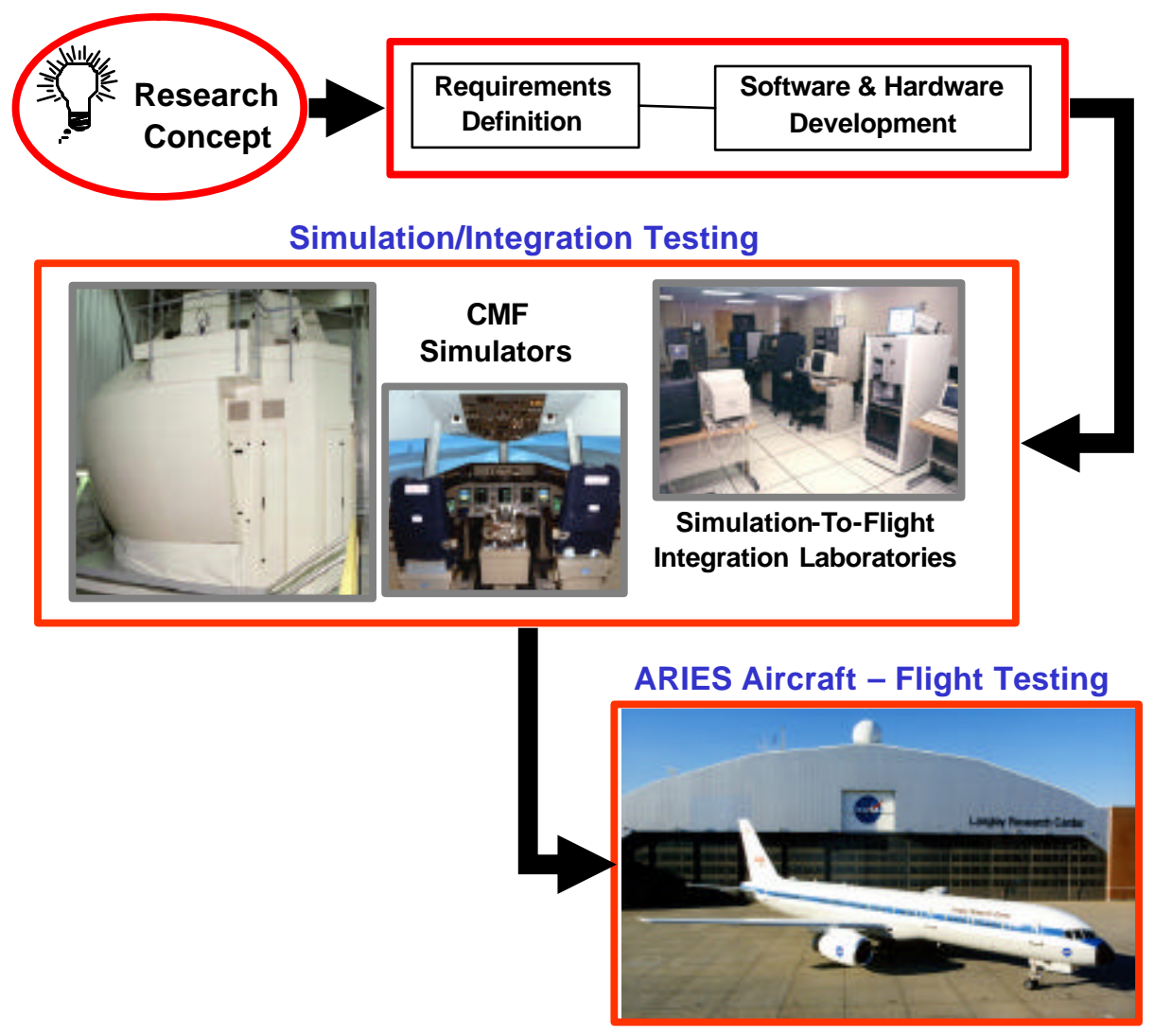

Figure 2 - Simulation-To-Flight Concept

\section{NASA LaRC Simulation-To-Flight Integration Laboratories}

One of the major design goals of the simulation-to-flight concept was for the Transport Research System (TRS) onboard the ARIES aircraft to readily accept software and/or hardware based experiments (either developed at LaRC or from a third party group) from the simulation environment to increase the efficiency and reduce the cost of implementing and conducting research tests. To satisfy this goal, common TRS hardware and software were implemented in both the integration laboratories, and in the ARIES TRS. All TRS modifications and/or upgrades across the TRF laboratories' are maintained under strict NASA configuration management processes and policies. These processes ensure that the functional tests of the TRS are identical and therefore provide projects an efficient, reliable, and consistent transition throughout the simulation-to-flight process. [2]

The RSIL and FSIL are architecturally the same; however, they are used for different purposes. The RSIL primary function is to support the development and testing of hardware and software in the simulation environment. The primary function of the FSIL is to support the testing of hardware and software that will be installed on the ARIES aircraft in conjunction with aircraft pallets. The RSIL and FSIL are usually utilized with components from the Flight Simulation Facility (FSF). 


\section{A. Flight Simulation Facility (FSF)}

FSSB supports flight simulation research projects with its unique set of simulation facilities. The Flight Simulation Facilities (FSF) are comprised of the Cockpit Motion Facility (CMF), the Differential Maneuvering Simulator (DMS), and the Visual Motion Simulator (VMS). The CMF is a multiple-cab, fixed- and motion-based flight simulation laboratory that contains the Integration Flight Deck (IFD) simulator cab, the Research Flight Deck (RFD) simulator cab, the Generic Flight Deck (GFD) simulator $\mathrm{cab}$, and the Research System Integration Laboratory (RSIL). [3]

The IFD cab closely resembles the B-757-200 forward flight deck (FFD) or cockpit and is used in support of flight-testing and aircraft systems integration studies. The RFD cab is an advanced subsonic flight deck used for full-crew-workload and full-aircraft-systems integration development and tests by the research community. The GFD is a general-purpose simulator cab that is used for conceptual designs of cockpits for advanced transport airplanes and other flight vehicles. The DMS provides a means of simulating two piloted aircraft operating in a differential mode (the pilots maneuver relative to each other) with realistic cockpit environment and a $360^{\circ}$ external visual scene for each of the two pilots. The VMS is a general-purpose simulator consisting of a two-person cockpit mounted on a six degree-of-freedom (DOF) synergistic motion base with a visual out-the-window scene that provides a field-of-view of 106 by 36 degrees. For more information about each of the FSF's simulators, readers may wish to visit he http://simulators.larc.nasa.gov web site.

Figure 3 illustrates the simulation architecture configuration used when running a flight simulation without an integration laboratory. A SCRAMNet ring establishes communication between the simulation host computer and any other systems used in the configuration.

\begin{tabular}{|c|c|}
\hline & Color Code \\
\hline 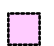 & Simulator-Specific \\
\hline 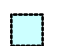 & Airplane-Specific \\
\hline 6 & Common Elements \\
\hline$L$ & AFD/RFD \& VME Interface \\
\hline
\end{tabular}

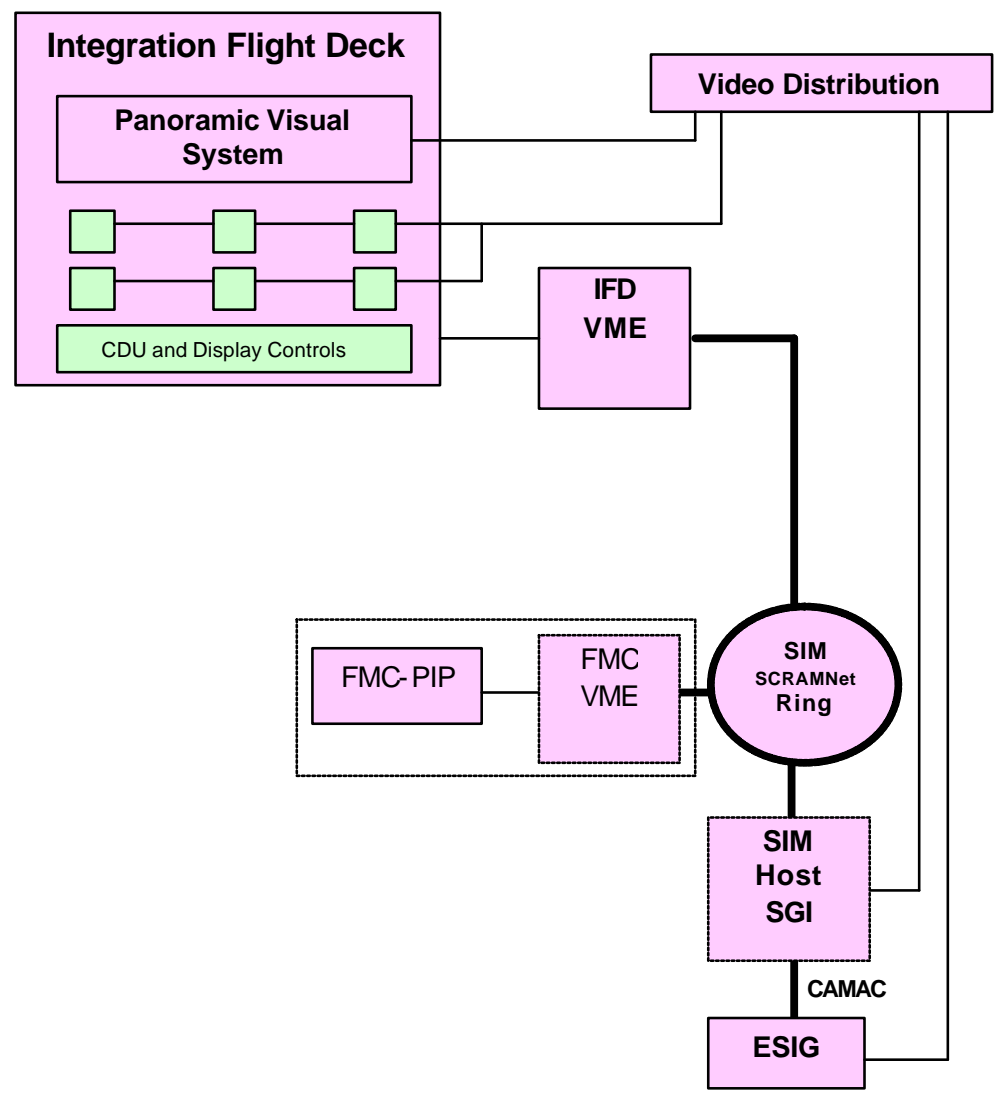

Figure 3 - Simulation Architecture 


\section{B. Research System Integration Laboratory (RSIL)}

The RSIL is a ground-based laboratory version of the ARIES on-board research system and is used for the development and testing of hardware and software systems while using the simulation facilities. The laboratory is composed of a Silicon Graphics ${ }^{\circledR}$ Incorporated (SGI $\left.{ }^{\circledR}\right)$ Ony x2® supercomputer connected to other flight subsystems ${ }^{* *}$ via the SCRAMNet ${ }^{2}+$ reflective memory network. $\dagger \dagger$ The Versabus Module Europe (VME) system chassis is used to provide a link between flight hardware and the SCRAMNet network. The VME chassis utilize a Motorola VME 1604 (PowerPC $604133 \mathrm{MHz}$ ) processort+ and may also use an analog I/O, digital I/O, synchro I/O, RS-232, ARINC 429 and other miscellaneous VME cards as required to communicate with flight hardware. The SCRAMNet+ network provides a flexible and high performance interconnection mechanism and relieves the Onyx 2 of low-level Input/Output (I/O) handling.

Figure 4 illustrates the simulation architecture configuration that supports the different integration laboratories. Note that there are two key SCRAMNet+ rings shown in this diagram. The SIM SCRAMNet loop establishes the network ring required to support communication (analog, discrete, and 429 signals) between the CMF simulator laboratory and RSIL subsystems. The Transport Research System (TRS) SCRAMNet loop establishes the network ring required to support the RSIL/FSIL utilizing the I/O Concentrator.

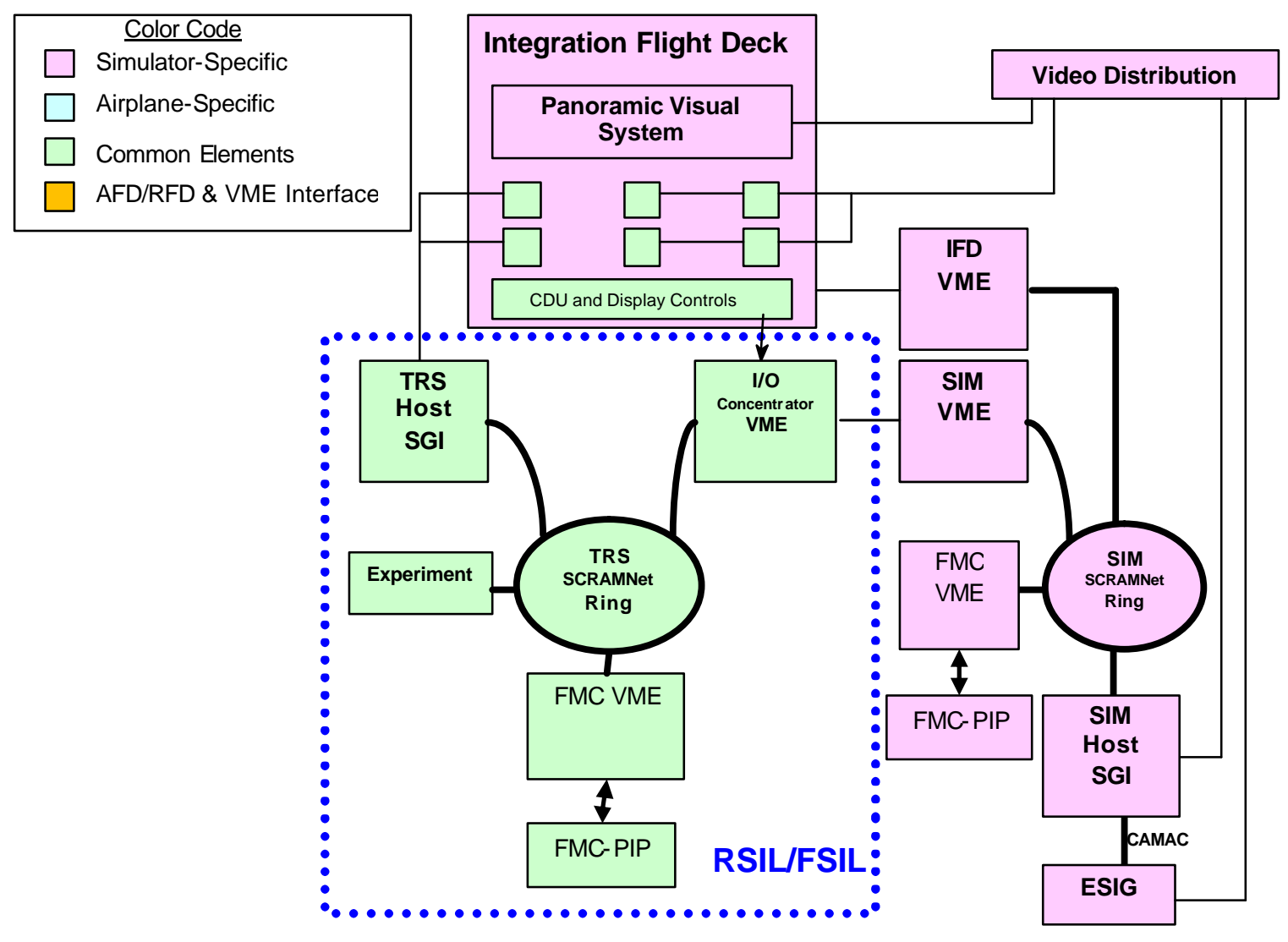

Figure 4 - Simulation Architecture of RSIL/FSIL Configuration

Each SCRAMNet+ ring consists of various computers ("node"). Each node currently contains a $2 \mathrm{MB}$ SCRAMNet+ card in its VME chassis. This configuration allows a flight application program to share

\footnotetext{
*** Silicon Graphics and Onyx are registered trademarks of Silicon Graphics, Inc.

${ }^{\dagger \dagger}$ SCRAMNet+ is a registered trademark of Systran Corporation.

\$ Note that processors are currently being upgraded to a Motorola VME 5100 (PowerPC $533 \mathrm{MHz}$ ).
} 
dynamically allocated blocks of SCRAMNet memory with other nodes. If any application modifies data stored in SCRAMNet memory, the change is propagated around the SCRAMNet ring until all of the nodes are updated. In the simulation SCRAMNet ring the simulation application is responsible for initializing the SCRAMNet+ hardware and managing the memory blocks use by this ring. Similarly, the TRS flight application is responsible for the same duties in the TRS SCRAMNet ring. The network protocol to distribute data around the SCRAMNet ring is implemented in the SCRAMNet card and therefore the retrieval of information from the network incurs no overhead and is transparent to each computer. [4]

In addition to utilizing high-speed SCRAMNet reflective memory rings, RSIL also uses a high speed Ethernet bus for transfer between subsystems. RSIL also features access to a local area and/or high-speed network and a video distribution network. When on ARIES, researchers/developers have internet access while on the ground connected to LaRCnet or in the air through satellite communication (SATCOM).

The FSF's RSIL/CMF baseline research system includes the following eight major subsystems:

- $\mathrm{CMF}$ simulator cabs - RFD, IFD, and GFD

- SGI Onyx supercomputers (four), two of which are scheduled to act as the simulation host and TRS host for a simulation-to-flight configuration.

- Simulation Interface reads data in the SCRAMNet+ interface from the SIM Loop and transmits the data through the 'copper' signal interface to the I/O Concentrator.

- Flight Management System (FMS) pallet houses the experimental Flight Management Computer (FMC) and a second experimental Computer Display Unit (CDU).

- I/O Concentrator (IOC), as its name implies, is the primary signal concentration point for the aircraft's subsystems data busses; 757 research sensors, research computer, Data Acquisition Systems (DAS), and other experimental system analog, digital, synchro and ARINC 429 signals. The DAS provides the data acquisition and storage of aircraft parameters from analog sensors, fiber optic link, and the aircraft 429 busses. The pallet converts the above signal information and places the data onto the SCRAMNet+ network. The pallet houses a $(32 \times 32)$ crossbar fiber optic Network Transparent Switch (NTS) that forms the research system's fiber optic network ring. Note that each IOC/NTS across the TRF are configured identically. In addition, it provides high-fidelity IRIG-B time to the research system by utilizing a Time Frequency Processor (TFP) card whose time code will be transmitted over the SCRAMNet+ network. Future TFP upgrades will utilize Global Positioning System (GPS) to synchronize to Universal Time Code (UTC).

- Operators Console (OPS) provides the RSIL/FSIL laboratory a reduced set of cockpit inputs simulating the Flight Deck Research Station (FDRS) for use when a full cab is not required. OPS consist of a Pilot Selection Panel (PSP), the FDRS experimental displays, CDU, Thrust Mode Select Panel (TMSP) and Experimental Display Control Panel (EDCP).

\section{Flight System Integration Laboratory (FSIL)}

The FSIL is a flight-test counterpart to the RSIL and supports ARIES research and baseline pallets. The FSIL is used for aircraft integration and preflight validation of key hardware and software systems destined for the ARIES. All electrical, mechanical, or environmental interfaces to the ARIES are developed and tested in the FSIL before aircraft installations are permitted. Hence, the FSIL is used for integration of an experiment to the TRS as well as providing a test bed for upgrades and maintenance of the TRS aboard the ARIES aircraft.

Although the FSIL resides in different location than the simulation facilities, the laboratory can be used with CMF resources via a long line fiber optic connection provided by the NTS. The FSIL baseline research system includes the following mayor subsystems: the Simulation Interface, Flight Control 
Interface, FMS, SGI computer, IOC, and OPS. Since FSIL subsystems are architecturally the same as RSIL, these subsystem have already been described in Section A.

As previously stated, the FSIL primary function is for ARIES integration and testing but can also support full flight simulations. The FSIL has proven invaluable for mechanically fitting and electronically integrating an experiment or baseline upgrade into the ARIES ship's systems without incurring the costs associated with operating the aircraft. Additionally, FSIL will support major ARIES research subsystems as further described in Section D.

\section{ARIES Aircraft Onboard Research Systems}

NASA LaRC's B757 ARIES aircraft provides unique capabilities and is used to conduct research to increase aircraft safety, operating efficiency and capacity of the national air traffic system. It is a vital research tool in support of the NASA's Aviation Safety and Aviation Systems Capacity Programs.

\section{ARIES - Transport Research System (TRS)}

The TRS primarily resides inside the rear cabin aboard the ARIES B-757 aircraft; it includes eleven major subsystems. These are contained within fourteen test pallets and research workstations in the main cabin, a power distribution and conversion system pallet; and an ARINC 429 Bus Isolation Box in the forward cargo bay, as well as, research displays in the Flight Deck (cockpit). [5] Figure 5 illustrates a typical ARIES pallet layout.
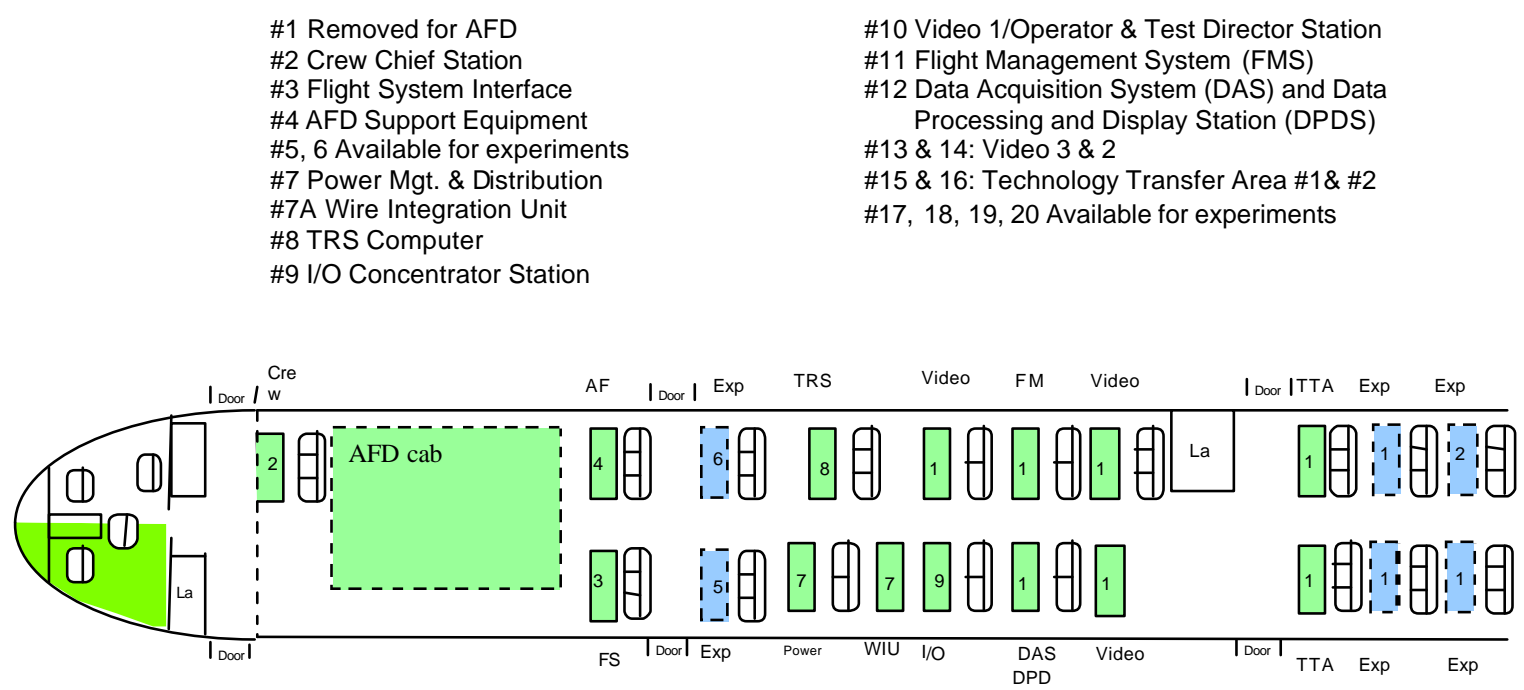

\#10 Video 1/Operator \& Test Director Station \#11 Flight Management System (FMS) \#12 Data Acquisition System (DAS) and Data

Processing and Display Station (DPDS) \#13 \& 14: Video 3 \& 2

\#15 \& 16: Technology Transfer Area \#1\& \#2

$\# 17,18,19,20$ Available for experiments

Figure 5 - ARIES Pallet Layout 


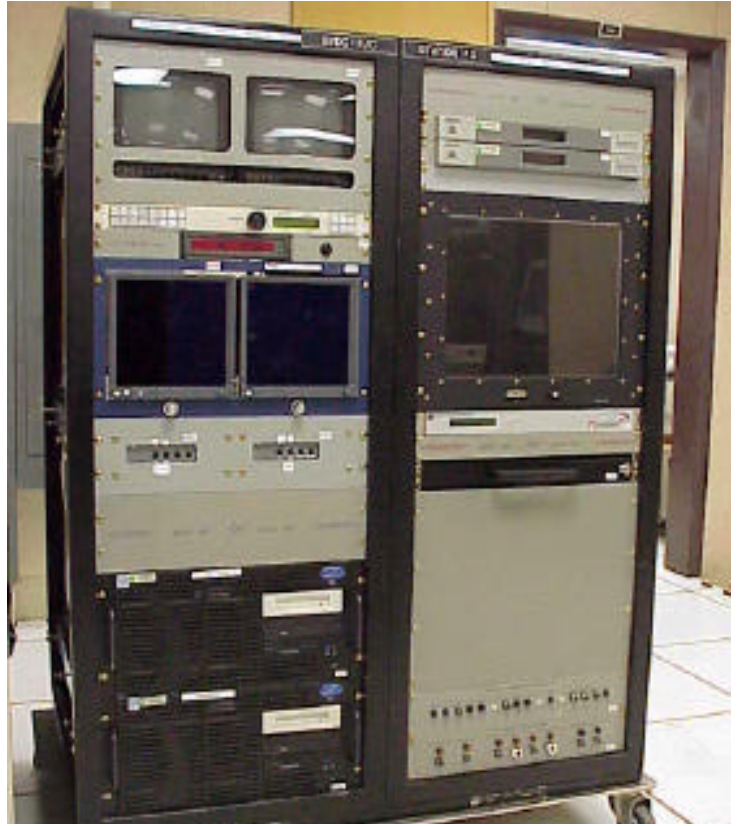

Figure 6 - Sample Research Pallet
As illustrated in Figure 6, each pallet consists of two 19 " equipment racks bolted side by side which are 30 " deep and flight hardened to crash loads of 9 Gs of force. Common pallet features include Dual Video Monitors, Video Select, UTC synchronized time display, Event Marker Button, side mounted cargo storage, and Power Distribution panels.

System operators monitor and interface with the subsystems at their pallets. These subsystems are the same functional subsystems as previously described for the RSIL and FSIL. Two additional subsystems are supported:

- Video Distribution and Recording System is provided for researchers and allows the latest in DVD recording.

- Flight Controls Interface (FCI) pallet provides flight controls systems, thrust management systems, and the PSP monitoring. It also provide the FDRS experimental displays and EDCP with power and setup control, as well as providing the HUD power, and signal conversion control and mixing.

\section{ARIES - Flight Deck Research Station (FDRS)}

Many of the evolving research efforts targeted to fly on ARIES require a realworld, out-the-window view, or the ability to fully control the aircraft through any given phase of flight including take-off, landing roll-out and taxi. Currently, the left seat of the FFD is the only location that allows both. The concept of the FDRS was developed to accommodate these research requirements, yet maintain the normal utility of the aircraft, and protect the level of safety and oversight needed to conduct viable research operations, see Figure 7. The TRS drives the FDRS and its electronic flight displays aboard the ARIES aircraft. The FDRS is located on

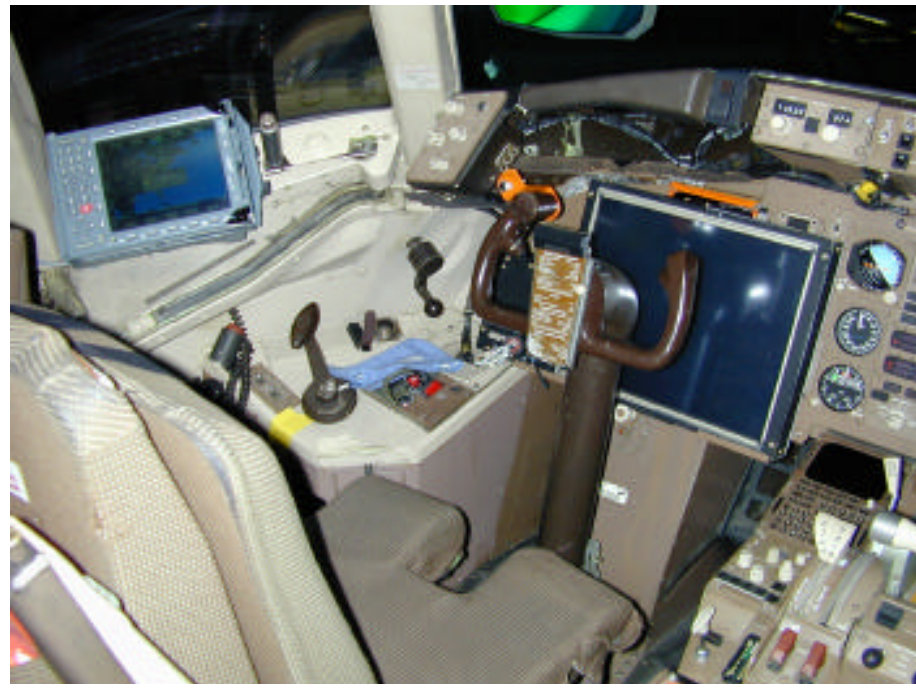

Figure 7 - Flight Deck Research Station (FDRS) onboard the ARIES aircraft the left-hand side of the cockpit. The FDRS is essentially a reconfiguration of the left side of the FFD for test subjects to evaluate flight systems and operational procedures. The FDRS provides an evaluation pilot the ability to assess the desired research concepts like advanced displays, cockpit procedures, or aircraft performance. [5]

When performing integration testing in the RSIL or FSIL, all of the aircraft state data reached the TRS Host computer by way of the IOC. In this configuration, the SIM VME provides the state data generated by the simulation to the IOC. Figure 8 illustrates the ARIES TRS architecture and how it mirrors the RSIL/FSIL configuration shown in Figure 4. On ARIES, the IOC is connected to an isolation box that gathers all of the aircraft's ARINC 429 signals and sensor data. All of the software running on the TRS in 
ARIES is identical to that used in the RSIL/FSIL configuration because the IOC pre sents a unified interface to the research applications running in the TRS.

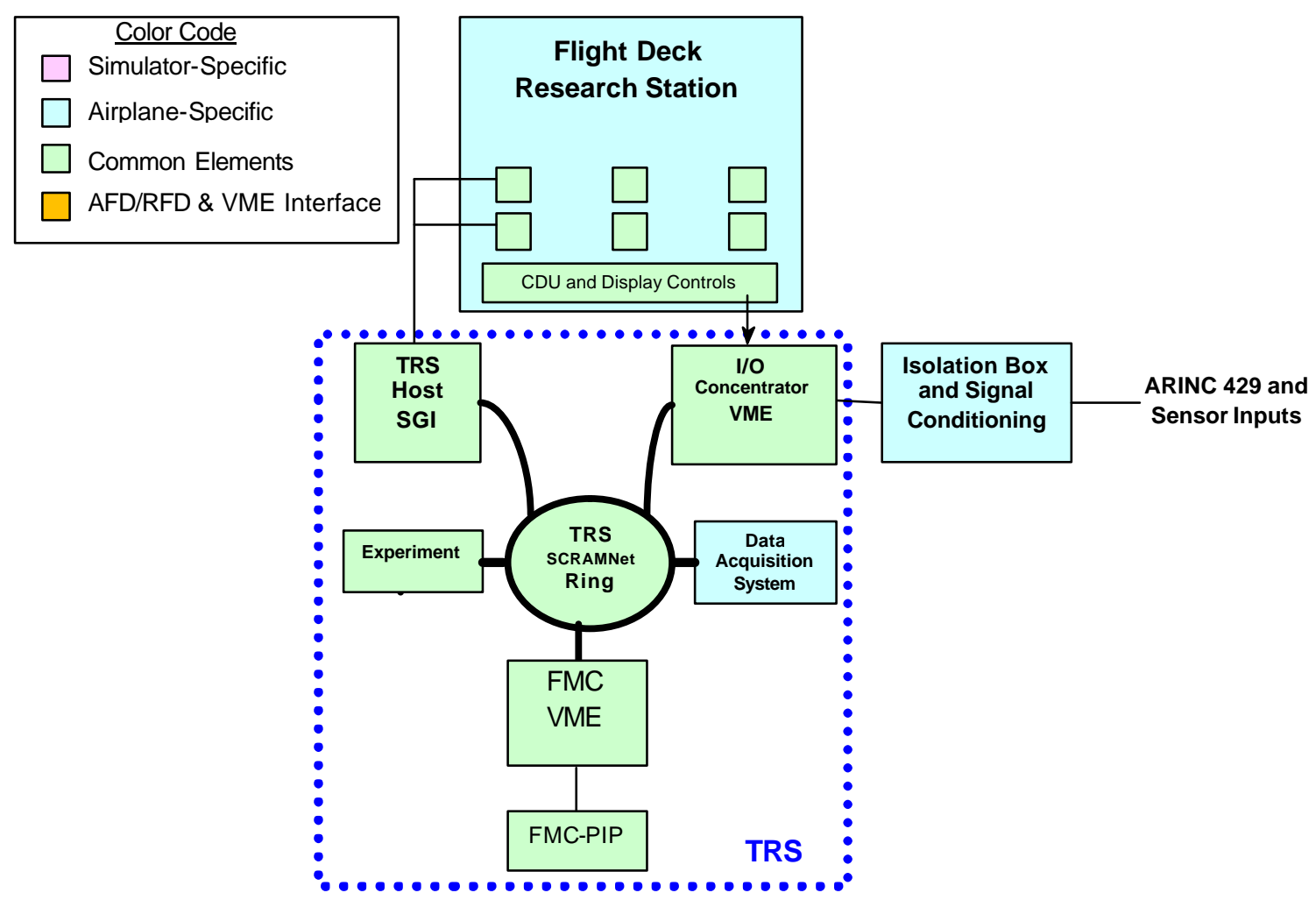

Figure 8 - ARIES TRS Architecture

\section{E. Future Transport Research Facility (TRF) Upgrade}

To extend the safety and research flexibility of the TRF, a fully functional research cockpit called the Aft Flight Deck (AFD) is being added to the forward cabin area of the ARIES aircraft. The AFD and the RFD simulator cockpit are intended to be identical in an effort to maximize hardware and software reuse, thereby permitting expeditious flow of projects from the simulator to the airplane. The AFD will be a one of a kind world class flying laboratory when integrated on the ARIES. Figure 9 illustrate how the AFD and RFD fit into the Simulation-To-Flight concept utilizing the Integration Laboratories with the ARIES aircraft. As with every TRF, all associated AFD software and hardware modifications and/or upgrades will be maintained under strict NASA CM processes and policies.

\section{NASA LaRC Simulation-To-Flight Integration Laboratories' Accomplishments}

Three main projects were successfully tested in the RSIL, integrated and tested for flight in the FSIL, and successfully flown on the ARIES aircraft. Two of these projects are winners of NASA's Turning Goals into Reality (TGIR) awards which are competed for at an agency wide level. These projects are briefly discussed and their significances are furthered outlined in the following section.

1. Airborne Information for Lateral Spacing (AILS) Project. The AILS project, conducted under the Aviation Systems Capacity (ASC) Program, was the first Simulation-to-Flight Concept validated in the RSIL, FSIL, and ARIES aircraft. This Terminal Area Productivity (TAP) project has won a NASA agency TGIR Award in 1999. The AILS project consisted of an airborne-based concept for independent instrument approaches to closely spaced parallel runways that enable the use of both runways during instrument 
approach conditions. All of the AILS hardwa re and software was developed and tested in the RSIL, and integrated and tested for flight in the FSIL.

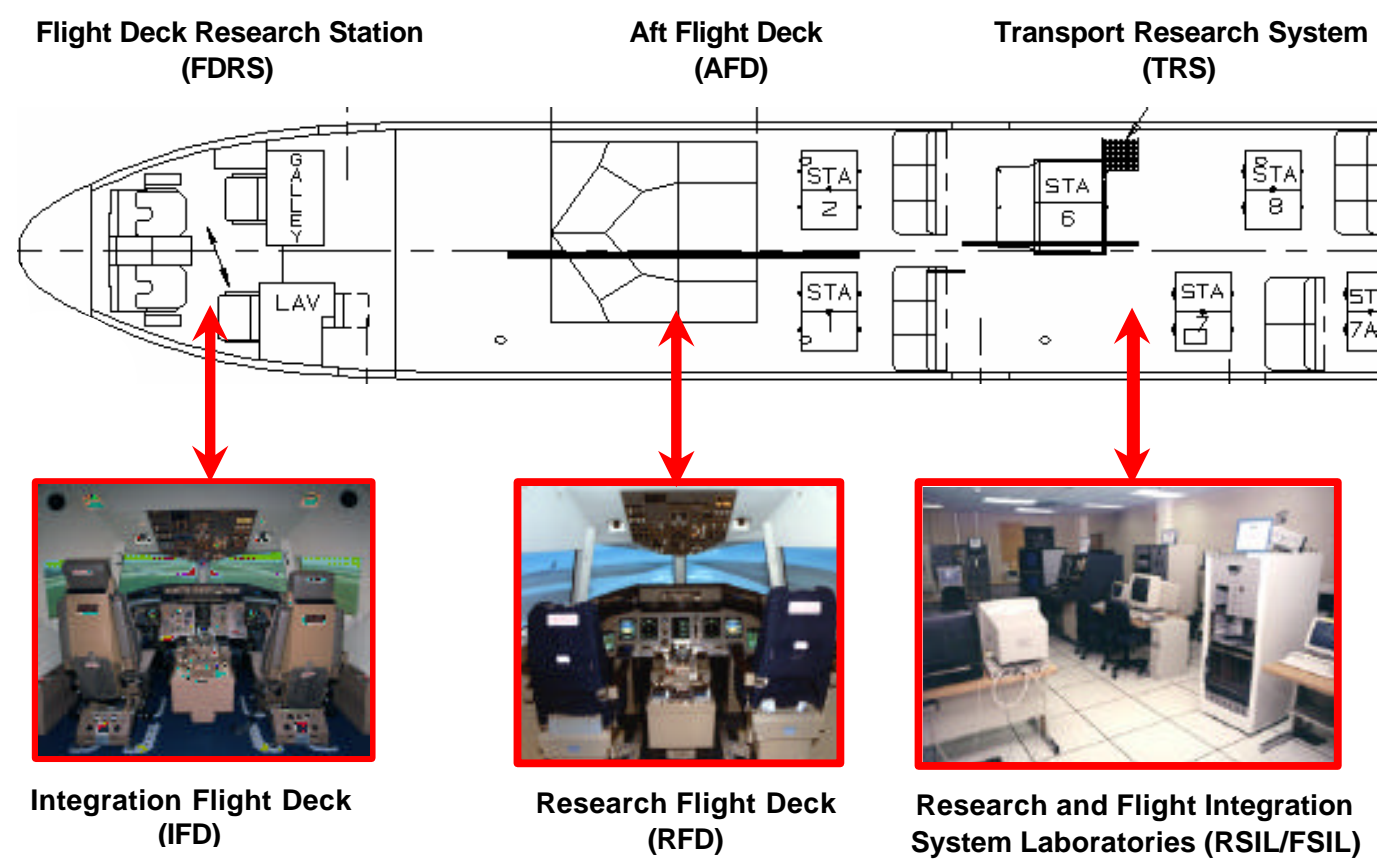

\section{Figure 9 - Transportation Research Facility (TRF) Integration}

An AILS Simulation Study was conducted in the NASA B-757 IFD simulator to study pilot acceptability (utilizing 16 participating airline pilots) to the AILS concept, pilot reaction times to AILS alerts, and minimum separation distances during "intrusion" scenarios. The AILS Simulation Study was completed in August 1999 followed by a joint NASA/Honeywell AILS Flight Test using the NASA ARIES aircraft and a Honeywell Gulfstream G-IV aircraft to validate the simulation findings.

AILS was a highly integrated project requiring the RSIL and both aircraft to be equipped with a Honeywell Traffic Alert and Collision Avoidance (TCAS) modified to include the LaRC developed AILS alerting algorithms and a Honeywell transponder with Automatic Dependent Surveillance-Broadcast (ADSB) data link capacity. The test aircraft flew Differential Global Position-coupled approaches using the data link with an operational Honeywell SLS -200 ground station at the NASA Goddard/Wallops Flight Facility.

The AILS concept safely maintains high airport acceptance rates for parallel runways with centerline spacing between 2500 and 4300 feet, a capacity not possible with current systems and procedures during low visible conditions. Given that most of the domestic airlines utilize hub airports with runway spacing in the range of 2500 to 4300 feet, the AILS capability can substantially improve airport capacity during inclement weather requiring instrument approaches. The AILS system can increase throughput of the air transportation system by safely maintaining high airport acceptance rates during visibility conditions that would drastically reduce acceptance rates with current systems and procedures.

AILS technology provides more accurate position determination and significantly reduces path deviation warning latency built into existing runway precision monitoring systems. With AILS, pilots receive timely cockpit warnings when flight path deviations occur, whether for their own or other threatening aircraft. Studies indicated that AILS can increase capacity $11 \%$ and generate savings of $\$ 30 \mathrm{M}$ 
per year at a single airport. Several airlines have expressed significant interest in continuing the maturation of AILS to an operational system. [6,7]

2. Synthetic Vision Systems (SVS) Project. The SVS project, conducted under the Aviation Safety Program (AvSP), demonstrates several new and promising display formats for both Head Down (conventional cockpit type displays) and Head Up (as are used on many fighters) Displays (HDD and HUD, respectively) for poor visibility conditions. [8]

The SVS project is developing display system concepts to improve pilot terrain/situation awareness by providing a perspective synthetic view of the outside world through an on-board database driven by precise aircraft positioning information updating via GPS-based data. This work is aimed at eliminating visibilityinduced errors and low visibility conditions as a causal factor to civil aircraft accidents, as well as replicating the operational benefits of clear day flight operations regardless of the actual outside visibility condition. SVS research and development activities at NASA LaRC are focused around a series of ground simulation and flight test experiments designed to evaluate, investigate, and assess the technology which can lead to operational and certified synthetic vision systems. [9] During 2001, utilizing the NASA ARIES aircraft equipped with experimental cockpit displays and computer systems, a flight research deployment to Colorado Springs and Eagle County Airport, Colorado was conducted to evaluate and demonstrate candidate SVS display concepts in an operationally realistic environment.

Additionally, SVS researchers successfully tested three unique technologies in flights over the Dallas/Fort Worth (DFW) International Airport. The system showed and sounded an alert if another aircraft or vehicle was nearing a conflict on the same runway. Once airborne, the SVS used a combination of HDD and HUD to provide the flight crew with a realistic world scene over a 10,000 square mile area surrounding the airport. The Runway Incursion Prevention System (RIPS) combined a HDD of an electronic moving map of airport runways and taxiways with a HUD that gave the pilot real-time guidance on the airport surface. [10] The airborne incursion alerting algorithms and associated alerting and airport surface displays required to support the RIPS were thoroughly tested and evaluated (involving 16 commercial airline pilots, who flew a total of 467 experiment scenarios) utilizing the RFD simulator. During this deployment, the SVS electronic moving map, HUD, and alerting systems effectively verified that the situations and errors that lead to runway incursions could be clearly avoided prior to serious hazards. This SVS Dallas/Fort Worth (DFW) Flight Test project was winner of a TGIR Award in 2000.

The SVS project, as part of an accident prevention strategy, has great potential to reduce accident rates by eliminating the number one cause of commercial jet aviation fatalities-controlled flight into terrain (CFIT) accidents, and two prime causes of general aviation accidents-CFIT and Loss of Control in poor visibility. In addition, SVS addresses the significant U.S. problem of an ever-rising runway incursion rate at our busiest airports.

3. Weather Accident Prevention (WxAP) Project. The WxAP project was established, by the NASA AvSP, given that weather has been identified as a causal factor in approximately $30 \%$ of all aviation accidents. The WxAP project purpose was the reduction of in-flight weather-related accidents and turbulence-related injuries via the development of enabling technologies. [11]

Within the WxAP project, one element was established to address the weather information needs of general, corporate, regional, and transport aircraft operators. This element, the Aviation Weather Information (AWIN) element, is developing the technologies in coordination with the FAA and industry that will provide accurate, timely and intuitive information to pilots, during the en-route phase of flight, to enable the detection and avoidance of aviation weather hazards. [12]

The AWIN project integrated on board sensors (such as the weather radar) and ground-based products (such as radar to produce a weather map for the pilots to allow them to divert around storms that may produce turbulence). Furthermore, a Turbulence Prediction and Warning System (TPAWS) program was conducted which attempts to measure the level of turbulence encountered and broadcast it to the ground and other aircraft. In this concept every aircraft becomes a turbulence detector and hence a picture of 
turbulence location and severity can be formed and shared with other aircraft. These research studies help to improve aviation weather information technologies and communications for system users.

The WxAP project was flown aboard the ARIES aircraft during the fall of 2000 and winter of 2001; and then flown during the summer of 2001 and the spring of 2002. For 2003, the WxAP project included the Rockwell Collins AWIN and the TPAWS experiments.

Other projects that were successfully tested in the RSIL, integrated and tested for flight in the FSIL, and successfully flown on the ARIES aircraft include:

- Advanced Terminal Area Approach Spacing (ATAAS) - Chicago Flight Test, 2003

- Aviation Security Research Proposal (ASERP) Automated Protected Area Avoidance System (APAAS), 2001

- Aircraft Noise Prevention Program (ANOPP) 757 Community Noise Flight Test at Wilmington, Ohio, 2000

- Winter Runway Friction Measurement, 1999 [13]

\section{Concluding Remarks}

The Simulation-to-Flight concept is a research development concept enabled by the NASA LaRC TRF and has reduced operational costs and increased testing efficiency for aeronautical research efforts at NASA. These facilities provide the unique capability of being able to test or validate an experimental system in a full simulation configuration, simulation/flight configuration, or full flight configuration. The facilities allow the use of a common set of software throughout a research projects life cycle. This reduces the amount of system level testing required before a project is conducted aboard the aircraft. Past projects have demonstrated that the simulation-to-flight concept is a productive and efficient means to develop and test new technology concepts to enhance the capacity, safety, and operational needs of the ever-changing national airspace system.

\section{Acknowledgments}

The NASA TRF and associated integration laboratories were not the sole idea of just one person. These facilities were created thanks to the many innovative ideas from the NASA researcher community. They not only facilitated a more user-friendly research environment but simultaneously enabled NASA to create a unique national asset that provides the American public and the world with safer, more efficient air transportation.

Finally, we would like to thank our stakeholders, the American citizens. The nation's trust and investment in NASA, less than 1 percent of the Federal budget, has helped to keep us on the leading edge of enabling technologies for the improvement of life on earth and beyond.

\section{References}

1. Chung, V. I., and Hutchinson, B. K.,"A Unique Software System For Simulation-To-Flight Research,“ AIAA Modeling and Simulation Technologies Conference \& Exhibit, Montreal, Canada, AIAA 2001-4057, August 6-9, 2001

2. Madden M., Configuration Management Plan For The Langley Standard Real-Time Simulation In C++ (LaSRS++), Version 2, [FSSB Internal Document], April 21, 1997.

3. Smith, R. M., A Description of the Cockpit Motion Facility and the Research Flight Deck Simulator. AIAA 20004174, Modeling and Simulation Technologies Conference and Exhibit, August 14-17, 2000

4. Geyer, D. W.; Madden, M. M.; Glaab, P. C.; Cunningham, K.; Kenney, P. S.; and Leslie, R. A.: "Managing Shared Memory Spaces in An Object-Oriented Real-Time Simulation", AIAA-98-4532.

5. Wusk, M. S.; “ARIES: NASA Langley's Airborne Research Facility,” AIAA 2002-5822, AIAA Aircraft Technology, Integration, and Operations (ATIO) 2002 Technical Forum, Los Angeles, California, October 1-3, 2002.

6. NASA LaRC Fact Sheet FS-1999-12-41-LaRC, December 1999. 
7. Rine, L. L, Abbott, T. S., Lohr G. W., Elliott D. M., Waller M. C., and Perry R. B., "The Flight Deck Perspective of the NASA Langley AILS Concept," NASA/TM-2000-209841, January 2000.

8. NASA LaRC Fact Sheet FS-2000-02-47-LaRC.

9. Bailey, R. E., Parrish, R. V., Kramer, L. J., Harrah, S., and Arthur III, J. J., "Technical Challenges In the Development of a NASA Synthetic Vision System (SVS) Concept," NATO RTO Enhanced and Synthetic Vision Systems, Ottawa, Canada, September 9-12, 2002.

10. Jones, D. R. "Runway Incursion Prevention System Simulation Evaluation," 21st Digital Avionics Systems Conference, Irvine, CA, October 27-31, 2002.

11. The NASA WxAP Systems Engineering Team, Concept of Operations for the NASA Weather Accident Prevention (WxAP) Project, Version 2.0 [online plan], April 30, 2003, URL: http://wxap.grc.nasa.gov/resources/pubs/WxAP_V2CONOPS_Final.pdf

12. McAdaragh, R. M., "Toward a Concept of Operations for Aviation Weather Information (AWIN) Implementation in the Evolving National Airspace System," NASA/TM -2002-212141, December 2002.

13. Yager, T. J., “Aircraft and Ground Vehicle Winter Runway Friction Assessment,” NASA/TM -1999-209142, May 1999. 